\title{
Ovine Lung Worm Prevalence and Associated Risk Factors in Merhabete District, North Shoa, Ethiopia
}

\author{
Niguagus leben ${ }^{1,2}$, Wassie Molla ${ }^{2}$, Tesfaye Bejiga ${ }^{1^{*}}$, Zelalem Yitayew $^{3}$ and Taye Solomon ${ }^{1}$ \\ ${ }^{1}$ Veterinary Drug and Feed Administration and Control Authority (VDFACA), P.O. Box 31303, Addis Ababa, Ethiopia \\ ${ }^{2}$ College of Veterinary Medicine, Gondor University, P.O.Box 196, Gondor, Ethiopia \\ ${ }^{3}$ North Shoa Zone Livestock and Fishery Administrative office, P.O.Box 336, Debre Birhan, Ethiopia
}

"Corresponding author: Tesfaye Bejiga, Veterinary Drug and Feed Administration and Control Authority (VDFACA), P.O. Box 31303, Addis Ababa, Ethiopia, E-mail: tetishb@yahoo.com

Received date: November 25, 2016; Accepted date: December 20, 2016; Published date: December 26, 2016

Copyright: (c) 2016 Leben N, et al. This is an open-access article distributed under the terms of the Creative Commons Attribution License, which permits unrestricted use, distribution, and reproduction in any medium, provided the original author and source are credited.

\begin{abstract}
A cross sectional study was carried out from October to December 2011 with the objectives of determining the prevalence of ovine lungworms and assessing the associated potential risk factors in Merhabete district, North Shoa Administrative Zone, Amhara National Regional State. A total of 384 faecal samples were collected from randomly selected sheep for the examination of first stage larvae using modified Beermann technique. Of these $52.34 \%$ were found positive for lungworm infection. The lungworm parasites identified were include $D$. filarial, M. capillaries and mixed infection with prevalence of $35.42 \%, 7.55 \%$ and $9.37 \%$, respectively. Among the potential risk factors assessed in the present study clinical signs, body condition and agro-climate were found to have significant association and play important role in the occurrence of lungworm infection. The prevalence was higher in animals showing clinical signs $(67.77 \%)$, having poor body condition $(63.89 \%)$, and originated from midland (57.95) than others. However, there was no statistically significant $(p>0.05)$ between the occurrence of ovine lungworm and the factors sex and age groups. In conclusion, this study indicated that lungworms are important internal parasites in the study area which impairs the productivity of sheep, implying the need for control intervention.
\end{abstract}

Keywords: Faecal; Lungworms; Merhabete district; Ovine; Prevalence

\section{Introduction}

In Ethiopia, agriculture is the mainstay of the country and also the major resource of employment and income. About $85 \%$ of the population live in the rural area and are primarily engaged in agriculture and related activities. Thus, agriculture directly or indirectly forms an important component of the livelihood of more than 60 million people in the country Atesmachew et al. [1].

In Ethiopia, livestock contribute about $30-35 \%$ of agricultural gross domestic product (GDP) and more than $85 \%$ of the farm cash income Benin et al. [2]. Among African countries, Ethiopia is known by having the highest number of livestock population. According to the recent estimate of livestock population of the country, Ethiopia is a home for about 54 million cattle, 25.5 million sheep and 24.06 million goats. From the total cattle population $98.95 \%$ are local breeds and the remaining are hybrid and exotic breeds. $99.8 \%$ of the sheep and nearly all goat population of the country are local breeds CSA [3].

Sheep are the dominant livestock providing up to $63 \%$ of cash income and $23 \%$ of food substance value obtained from livestock production Bogale et al. [4] Ibrahim and Godefa [5]. Hence, an increase in sheep production enables to maintain self sufficiency in meat consumption for growing number of human population and also to increase export earnings Flecher and Zelalem [6]. However, this huge potential resources available in the country, several factors especially disease constraint their full utilization. The reason being predominance of infectious and parasitic disease, age old traditional management system, lack of genetic selection for good performance coupled with under and malnutrition and absence of well-developed market infrastructure MoA [7]. From these the respiratory diseases have been identified as an important problem of sheep in the highlands of Ethiopia for the last two to three decades. It may account for up to $54 \%$ of the overall mortality of sheep in central high lands of Ethiopia Mukasa - Mugerwa et al. [8].

Among the respiratory diseases, Endo-parasites such as Dictyocaulidae and certain Metastrongylidae are known to exist in East Africa (Ethiopia, Kenya, and Tanzania) and South [9]. Lungworms particularly Dictyocaulus filaria can suppress the immunity of the respiratory tract [10] and causes death, poor weight gain or loss of body weight as well as greatly affects the potential productivity of sheep industry in the areas where it is prevalent.

Control of these parasites is essential for exploiting the potential of small ruminant production. For proper control, knowledge of parasitic diseases and their dynamics is essential. For this reason a study of epidemiology of each parasitic disease should be carried out in area where control is targeted Radostits et al. [11].

The incidence of parasitic diseases, including respiratory helminthiasis varies greatly from place to place depending on the relative importance of many factors. In this regard, although few studies were conducted so far in the North Shoa zone, there was no as such detail investigation to lungworm in Merhabete district. Thus, the present study was designed with the general objective of investigating the occurrence of ovine lungworm in the district. In line with this the specific objectives were to determine the prevalence of ovine lungworms and to assess the associated potential risk factors with the occurrence of lung worms. 
Page 2 of 5

\section{Materials and Methods}

\section{Study area}

The study was carried out from October to December, 2011 in Merhabete district of North Shoa Administrative Zone, Amhara National Regional State. The district is found in the central highlands of Ethiopia which is located at a distance of $180 \mathrm{~km}$ North of Addis Ababa.

The district covers 99540 hectares of land and divided in to 23 rural and 2 urban kebeles. The topographic data indicates that $20 \%$ plain, $15 \%$ mountain and $65 \%$ rugged. The altitude of the area varies from 1179-2644 m.a.s.l. The district has three agroclimatic zones with percent coverage of $5 \%$ highland, $65 \%$ midland and $30 \%$ lowland. The mean annual rainfall ranges between 838-1421 mm MARDO [12].

The total number of population of the district is 133448 out of this $88.86 \%$ dwell in the rural area and 11.14 dwell in urban area [12]. According to MARDO, basic data the population of livestock comprises of 121380 cattle, 9457 sheep, 40264 goats, 15289 equine and 64829 poultry.

\section{Study animals}

The study animals, sheep in the study area maintained under extensive system in small household flocks of mixed age groups and sexes and they were all indigenous (local breed) were included in the study.

\section{Study design}

Cross sectional type of study was carried out in Merhabete district starting from October to December 2011. Ten peasant associations were selected proportionally from each agro-climatic zone by using simple random sampling technique and a total of 384 animals were randomly selected from these areas. In this study, sex, age, respiratory signs, body condition and agro climate were considered as risk factors for the occurrence of lungworm in sheep and data related to these factors were recorded during faecal sampling. The age was categorized in to two groups (young and adult), those sheep with age less than two years were considered as young and greater or equal to two years adult Cringol et al. [13]. Regarding body condition, the animals categorized in to three groups (good, medium and poor body condition) and further grouped in to two based on clinical sign observed (i.e. coughing, nasal discharge, sneezing, dyspnea) [14].

\section{Sample size determination and sampling technique}

The sample size for this study was determined by using the formula given by Thrusfield [15], using simple random sampling technique was employed to select each and every animal included in the study. By rule of thumb where there is no information for an area it is possible to take $20 \%$ or $50 \%$ expected prevalence. Therefore, in this study the sample size is determined to be 384 by using $50 \%$ expected prevalence at $5 \%$ desired precision and 95 confidence interval as follows.

$$
\mathrm{n}=\frac{\left(\mathrm{Z}^{2} \mathrm{xP}(1-\mathrm{p})\right.}{\mathrm{d}^{2}}=\frac{1.962 \times 0.5(1-0.5)}{0.0025}=384
$$

Where, $\mathrm{n}=$ sample size

$\mathrm{P}=$ expected prevalence
$\mathrm{D}=$ desired level of precision $(5 \%)$

\section{Study methodology}

Fecal examination: Faecal samples were collected directly from the rectum of selected animals in screw capped glass bottle (universal bottle) and packed in ice box. While collecting faecal sample sex, age, body condition, respiratory sign and agro climate are properly recorded on the prepared format. In the laboratory, faecal sample examination for the presence of L1 larvae was conducted using modified Baermann technique Urquhart et al. [16]. Ten gram of faeces was taken and the specimens were wrapped enclosed with double layer of gauze fixed on to a string rod and submerged in a clean glass tube filled with warm water (approximately $40^{\circ} \mathrm{C}$ ). The whole apparatus was left for $24 \mathrm{~h}$ overnight. So that the larvae left the faeces, migrated through the gauze and settled at the bottom of the glass finally the supernatant discarded Urquhart et al. [16]. After that, a small amount of (3-5 ml) fluids transfer in to a microscope slide using Pasteur pipette then it was examined under low power of the microscope. A drop of $1 \%$ iodine solution was added to the positive slides to immobilize the larvae for the identification of species Urquhart et al. [16]. Then, the result was recorded on the prepared format.

\section{Data analysis}

The data collected during sampling and laboratory findings were entered and stored in MS-excel. Stata 11 software package was used to perform the statistical analysis. Ovine prevalence was calculated by dividing the number of sheep infested with lungworm to the total number of sheep sampled. Pearson chi-square $\left(\chi^{2}\right)$ test was employed to assess the existence of association between occurrence of ovine lungworm and different potential risk factors considered in the study. For this analysis $\mathrm{P}<0.05$ were considered significant whereas $\mathrm{P}>0.05$ considered not significant.

\section{Results}

\section{Prevalence of lungworm infection}

Out of a total of 384 sheep examined over the study period, $52.34 \%$ (201/384) were positive for lungworm infection. The prevalence of $D$. filaria, M. capillaris and their mixed infection were found to be 136 (35.42\%), 29 (7.55\%) and 36 (9.4\%), respectively (Table 1).

\begin{tabular}{|l|l|l|l|}
\hline Lungworm species & $\begin{array}{l}\text { No of sheep } \\
\text { examined }\end{array}$ & $\begin{array}{l}\text { No } \\
\text { positive }\end{array}$ & Prevalence (\%) \\
\hline D. filaria & 384 & 136 & 35.42 \\
\hline M. capillaris & 384 & 29 & 7.55 \\
\hline Mixed infection & 384 & 36 & 9.37 \\
\hline Total & 384 & 201 & 52.34 \\
\hline
\end{tabular}

Table 1: Prevalence of ovine lungworm by parasitic species.

\section{Risk factor analysis}

In this study the following variables such as sex, age, respiratory signs, body condition and agroclimate zone were assumed to be risk factors for the occurrence of lungworm in sheep. The findings on these 
Page 3 of 5

factors and association between the prevalence of the disease and the risk factors were as presented here below.

Sex: The prevalence of ovine lungworm was higher in female $(53.87 \%)$ than male $(52.27 \%)$, however, no significant $(\mathrm{p}>0.05)$ difference was observed in prevalence rate of lungworms between sex (Table 2).

\begin{tabular}{|l|l|l|l|}
\hline Sex & $\begin{array}{l}\text { No of sheep } \\
\text { examined }\end{array}$ & No of positive & Prevalence (\%) \\
\hline Female & 245 & 132 & 53.87 \\
\hline Male & 139 & 69 & 52.27 \\
\hline Total & 384 & 201 & 52.34 \\
\hline
\end{tabular}

Table 2: Prevalence of lungworm infection in male and female. $\mathrm{X}^{2}=8.3546, \mathrm{P}=0.138$.

Age: The age wise prevalence on this study showed that a little bit higher lungworm infection in young sheep $(53.47 \%)$ than adult sheep $(51.67 \%)$, however, the difference was not statistically significant ( $>>0.05)$ (Table 3).

\begin{tabular}{|l|l|l|l|}
\hline Age & $\begin{array}{l}\text { No of animals } \\
\text { examined }\end{array}$ & No of positive & Prevalence (\%) \\
\hline Young & 144 & 77 & 53.47 \\
\hline Adult & 240 & 124 & 51.67 \\
\hline Total & 384 & 201 & 52.34 \\
\hline
\end{tabular}

Table 3: Prevalence of lungworm infection in different age groups. $\mathrm{X}^{2}=9.8151, \mathrm{P}=0.081$.

Respiratory signs: High prevalence of lungworm was observed in sheep that were showing clinical signs than apparently normal animals. The presence of clinical signs were significantly $(\mathrm{p}<0.05)$ associated with lungworm infection (Table 4).

\begin{tabular}{|l|l|l|l|}
\hline Respiratory signs & $\begin{array}{l}\text { No of animals } \\
\text { examined }\end{array}$ & $\begin{array}{l}\text { No } \\
\text { positive }\end{array}$ & Prevalence (\%) \\
\hline Absent & 142 & 37 & 26.06 \\
\hline Present & 242 & 164 & 67.77 \\
\hline Total & 384 & 201 & 52.34 \\
\hline
\end{tabular}

Table 4: Prevalence of lungworm infection in relation to respiratory signs. $\mathrm{X}^{2}=72.9310, \mathrm{P}=0.000$.

Body condition: In this study animals having poor body condition were found to have higher prevalence of ovine lungworm infection than moderate and good body conditions and the difference among the different body condition categories was statistically significant $(\mathrm{p}<0.05)$ (Table 5).

\begin{tabular}{|l|l|l|l|}
\hline Body condition & $\begin{array}{l}\text { No of animals } \\
\text { examined }\end{array}$ & No of positive & Prevalence (\%) \\
\hline Poor & 108 & 69 & 63.89 \\
\hline Moderate & 268 & 130 & 48.51 \\
\hline
\end{tabular}

\begin{tabular}{|l|l|l|l|}
\hline Good & 8 & 2 & 25 \\
\hline Total & 384 & 201 & 52.34 \\
\hline
\end{tabular}

Table 5: Prevalence of ovine lungworm infection based on body condition. $\mathrm{X}^{2}=14.7887, \mathrm{P}=0.014$.

Agro-climate: In the present study, the occurrence of lungworm was $54.17 \%, 57.95 \%$ and $41.88 \%$, in highland, midland and low land areas, respectively. Statistically significant $(\mathrm{p}<0.05)$ variation in lungworm infection was observed among the three agro- climatic zones (Table 6).

\begin{tabular}{|l|l|l|l|}
\hline Agro climates & $\begin{array}{l}\text { No of animals } \\
\text { examined }\end{array}$ & No of positive & Prevalence (\%) \\
\hline Highland & 72 & 39 & 54.17 \\
\hline Midland & 195 & 113 & 57.95 \\
\hline Lowland & 117 & 49 & 41.88 \\
\hline Total & 384 & 201 & 52.34 \\
\hline
\end{tabular}

Table 6: Prevalence of ovine lungworm infection in relation to agroclimates. $\mathrm{X}^{2}=54.2093 \mathrm{P}=0.000$.

\section{Discussions}

The present study revealed the importance of lungworm infections. In these study area with an overall ovine lungworm infections rate were $52.34 \%$ these finding is closely agree with previous studies done by Tefera, [17] around kombolcha and Dessie, Sefinew [18] in six districts of Wollo and Habitamu [19] in and around Debre Birhan with prevalence of $50 \%, 53.6 \%$ and $52.25 \%$ respectively. But it is relatively lower than reported by Zelalem [20], in Bassona Worena district with a prevalence of $62.67 \%$. However it is higher than that of Regassa et al. [21] in and around Dessie and Kombolcha and Basaznew Bogale et al. [22] reported prevalence of $48.2 \%$ and $43.33 \%$ respectively. The variation in the overall prevalence rate in different areas might be due to differences in nutritional status, level of immunity, management practice of the animal, rain fall, humidity and temperature differences and season of examination on their respective study area Kebede et al. [23].

With regard to the species of lungworms, it was identified that $D$. filaria and $M$. capillaries occurred with prevalence of $35.42 \%$ and $7.55 \%$, respectively. A mixed infection with the two lungworms was also occurred at prevalence of $9.37 \%$. The prevalence of $D$. filarial in this finding is supported by [19] in and around [24], in Bassona Worena district with prevalence of $36.25 \%$ and $38.1 \%$ respectively. In contrast to these findings, sisay [25] in Bahir Dar and Basaznew Bogale et al. [22] in Dessie zuria district reported that M. capillaries were the most prevalent in their studies. The possible reason for the predominance of $D$. filaria might be attributed to the difference in the life cycles of the parasites. $D$. filaria has a direct life cycle and requires shorter time to develop to an infective stage. After ingestion, the larvae of these parasites can be shed with feces within 5 weeks. Unlike to $D$. filaria, the transmission of $M$. capillaris is epidemiologically complex event involving host, parasite and intermediate host $[23,26]$.

In the current study higher level of prevalence were observed in female sheep than male but it was insignificant and this result agrees with that of [27], who reported insignificant difference of lungworm infections concerned on sheep sex. But contrast with the report of [25] 
and [28] who reported significant difference of lungworm infection between male and female sheep. This high prevalence in female could be accredited to some of the physiological facts meaning the pre parturient relaxation of resistance can be result in the in ability to expel the worm Craig, TM [29]. In addition farmers are kept male animals for different purposes like fattening, breeding and as a result male were given more dewormed than females.

This study showed that, the prevalence of lungworm infections affected by $D$. filaria and $M$. capillaries were observed higher prevalence in young sheep (53.47\%) than adult sheep (51.66\%), with no significant between the prevalence's of the different age groups. This report agree with Mekonnen et al. [30] who report that young sheep were found to be infected more than adults. This might be associated with apparent ability of the host to develop acquired immunity so that adult animals have the lowest infection and the lowest prevalence Urquhart et al. [16].

The prevalence of lungworm was significantly $(\mathrm{p}<0.05)$ higher in the animal showing clinical sign (67.76\%) than apparently normal (26.05\%). This finding agrees with the result of [31] who reported the higher prevalence of lungworm infection in the animal showing clinical signs $(86.8 \%)$ than apparently normal $(57.1 \%)$. The reason attributed for such difference could be due to the stage of the parasite Fraser [32].

With regard to body condition, the prevalence of lungworm infection was higher $(63.89 \%)$ in animals of poor body condition than those of medium (48.51\%) and good (25\%). The difference was significant $(\mathrm{p}<0.05)$. This finding agreed with Muhammed et al. [33], Sisay [25] and Zelalem [20]. They reported that high prevalence was found in animals which had poor body condition. This might be associated with the nutritional management of animals. Poor body condition occurred as a result of lack of feed or nutritional management. This may lead to lack of resistance to infection and contribute for increased prevalence rate in poorly conditioned animals. Furthermore, considerable weight loss was associated with infection as a result of $D$. filaria [34], poorly nourished sheep and goat appeared to be less competent in getting rid of lungworm infection. Evidently, the infection with a parasite by itself might results in progressive emaciation of the animals [35]. The infestation by itself might results in progressive emaciation of the animals.

The prevalence of lungworm infection in various agro- climatic zone were shown significant difference $(\mathrm{p}<0.05)$ in the study area. This is in line with the study result of Birtukan [28] in and around Debre Brhan. This might be due to the effect of altitude is attributable to climatic parameters. That is the survival and development of lungworm larvae is favoured by low moisture content and high humidity.

\section{Conclusion and Recommendation}

In general this study on ovine lungworm infection in Merhabete district revealed an overall prevalence of $52.34 \%$. Two respiratory nematodes, $D$. filaria and $M$. capillaries were identified. It is found that animals under relatively good body condition, without respiratory signs and originated from lowland were less affected than those having poor body condition, with respiratory signs and originated from midland. $D$. filaria was found the most dominant lungworm species. Based on the above conclusion, the following points are recommended.
Animal health professionals should create awareness for animal owners to practice regular deworming of their animal.

The district administrative bodies should enforce application of rotational and/or zero grazing system.

Strategic anti-helmenthic drug treatment should be implemented.

Daily feed supplement according to the requirement should be exercised so as to improve body condition and immune resistance.

It is quite difficult to establish the seasonality of the infection on the basis of facts and figures presented by this study. Therefore, further works were recommended to study the seasonal pattern of lung worms and define other species in this region.

\section{References}

1. Atesmachew B, Girma T, sonder K, Peden D, Yilma J (2006) Comparative assessment of forage and livestock density in tekeze river basin. Ethiop Vet J 10: 25-36.

2. Benin S, Ehui S, Pender J (2002) Policies for livestock development in the Ethiopian high lands: In socio economics and policy research working paper, Addis Ababa Ethiopia 5: 491.

3. CSA (2013) Agricultural Sample Survey, 2012/13 (2005 E.C.). Volume II: Report on Livestock and livestock characteristics (Private peasant holdings). Statistical Bulletin-570. Addis Ababa: Central Statistical Agency (CSA), Federal Democratic Republic of Ethiopia.

4. Bogale B, Ebre A, Melaku A (2012) Ovine lungworm infection, prevalence, species composition and associated risk factors in Dessie Zuria district, northestern Ethiopia. Afri J Bas and App Sci 4: 73-76.

5. Ibrahim N, Degefa Y (2012) Prevalence of Ovine Lung Worm Infection in Mekelle Town, North Ethiopia. Int J Vet Med 9: 1-15.

6. Fletcher I, Zelalem LC (1998) Ruminant productivity in Ethiopia in mixed farming system. Processing of 4 th, National livestock improvement conference, 13-15, November, IRA, Addis Ababa, Ethiopia.

7. MOA (1998) The role of village dairy cooperative in dairy development: prospect for improving dairy in Ethiopia. Proceeding of a work shop of organized by SDDP, pp: 22-24.

8. Mukasa- Mugerwa E, Lahlou-kassi A, Anindo D, JEO Rege, Tembely S, et al. (2000) Between and within breed variation in lamb survival and risk factors associated with causes of mortality in indigenous tropical sheep. Small Ruminants Res 37: 1-12.

9. Tony W (2006) The veterinary epidemiology and economic research unit, school of agriculture, policy and development in: diseases of small ruminants in Ethiopia, Netherlands /UK, pp: 6-8.

10. Gelagay A, Leakemariam Y, Esayas G, Selam T, Kassahun A (2005) Epidemiologic and Serologic Investigation of Multifactorial Respiratory Disease of Sheep in the Central Highland of Ethiopia. Intern J Appl Res Vet Med 9: 74-78.

11. Radiostits OM, Blood DC, Gray CC (1994) Veterinary medicine (8th edtn.). London, UK, pp: 17-63.

12. MARDO (2002) Merhabete district Agricultural and Rural Development Office basic data 2002.

13. Cringol G, Rinaldi L, Veneziano V, capelin G, Malone JB (2002) Acrosssectional coprological survey of liver fluckes in cattle and sheep from an area of the southern Italian Apennines. Vet Parasitol 108:137-143.

14. Girma A (2008) Ethiopian sheep and goats productivity improvement program, Debre Birhan, Ethiopia, pp: 16.

15. Thrusfield M (1995) Veterinary Epidemiology (2nd edtn.). Black Well Science, UK, pp: 182-189.

16. Urquhart GM, Armour J, Dunca AM, Jennings FW (1996) Veterinary Parasitology. 2nd edn., Scotland, Black Well Science, pp: 39-58.

17. Tefera S (1993) Prevalence of ovine lungworms around dossier and Kombolcha, DVM thesis, FUM, Addis Ababa University, Debrezeit Ethiopia. 
Citation: Leben N, Molla W, Bejiga T, Yitayew Z, Solomon T (2016) Ovine Lung Worm Prevalence and Associated Risk Factors in Merhabete District, North Shoa, Ethiopia. J Bacteriol Parasitol 7: 298. doi:10.4172/2155-9597.1000298

Page 5 of 5

18. Sefinew A (1999) A survey on small ruminant lung worm infection in six districts of Wollo; in DVM thesis., FVM, Addis Ababa University, Debrezeit, Ethiopia.

19. Habtamu T (2010) Ovine verminous pneumonia survey in Debre Birhan North Shoa. DVM thesis, FVM, university of Gondar, Gondar, Ethiopia.

20. Zelalem Y (2011) Lung worm, infection in ovine prevalence and associated risk factors in Basona and Worran district, BSC Thesis, FVM, University of Gondar, Gondar, Ethiopia.

21. Regassa A, Toyeb M, Abebe R, Megerssa B, Mekibib B, et al (2009) Lungworm infection in small animal ruminants: prevalence and associated risk factors in Dessie and Kombolcha districts, North Eastern Ethiopia. Vet Parasitol 169: 144-148.

22. Basaznew B, Ayalew E, Achenef M (2012) Ovine Lungworm Infection: Prevalence, Species Composition and Associated Risk Factors in Dessie Zuria District, Northeastern Ethiopia. Afr J Basic Appl Sci 4: 73-76.

23. Kebede S, Menkir S, Desta M (2014) On farm and Abattoir study of Lungworm infection of small ruminants in selected areas of Dale District, Southern Ethiopia. Int J Curr Microbiol App Sci 3: 1139-1152.

24. Fantahun G (2011) Prevalence of ovine lungworm and associated risk factors in bassona worana district, BSC Thesis, Kombolcha College of Agriculture, Wollo University.

25. Sisay A (1996) Prelimary study on the prevalence of ovine lung worm infection in and around Bahir Dar, DVM thesis, FVM, Addis Ababa University, Debrezeit, Ethiopia.

26. Kahn C (2005) The Merck Veterinary Manual.Ninth Ed. Merck and co., INC., white house station, USA, pp: 215-256.

27. Tesfalem Z (2010) Lungworm infection in ovine: Prevalence and associated risk factors in Debre Birhan municipality Abattoir. DVM thesis, FVM, Hawassa University, Hawassa, Ethiopia.
28. Birtukan B (2010) Study on prevalence of ovine lungworm in DebreBirhan sheep and forage seed multiplication center around Debre-Birhan. DVM thesis, FVM, Haramaya University, Haramaya, Ethiopia.

29. Craig TM (1998) Epidemiology of internal parasites, effect of climate and host on reproductive cycle in parasite survival. Small ruminants for the mixed animal practitioner. Wester Veterinary Conference, Las Vagas, Nevada, USA.

30. Mekonnen A, Abebe F, Yohannes E (2011) Study on the prevalence of lungworm infection in small ruminants in gondor town, Ethiopia. Vet Res 4: 85-89.

31. Eyob E, Matios L (2013) The prevalence and risk factors associated with ovine lungworm infestation in the Asella province, Central Ethiopia. Global Sci Res J 025-030.

32. Flaser CM (1991) The veterinary manual: A hand book of diagnosis, therapy and disease prevention and control for the veterinarians (7th edtn). Merck and co., USA, pp. 714-717.

33. Muhammed H, Alebachew T, Ayichew T, Destaw E (2016) Study on Lungworm and Associated Risk Factors of Small Ruminants in Hitosa Woreda, Ethiopia, Wolaita Sodo University, School of Veterinary Medicine, Ethiopia. Global Veterinaria 17: 303-309.

34. Thomson R (2008) Special Veterinary pathology, BC Decker. Inc. Toronto Philadelphia, pp: 112-113.

35. Radostits O, Gay C, Hinchcliff K, Constable P (2007) Veterinary Medicine. A Text book of the disease of cattle, horses, sheep, pigs and goats (10th edtn). Bailler Tindal, London, USA, pp: 1568-1569. 